\title{
ЛИТЕРАТУРОВЕДЕНИЕ
}

\author{
Научная статья \\ УДК 821.161 .1 \\ DOI: $10.18101 / 2686-7095-2021-1-41-48$

\section{ДРАМА ГЕРОЯ РОМАНА И. С. ТУРГЕНЕВА «РУДИН»: МЕЖДУ ЗАПАДОМ И РОССИЕЙ}

\author{
(C) Башкеева Вера Викторовна \\ доктор филологических наук, профессор, \\ Бурятский государственный университет имени Доржи Банзарова \\ Россия, 670000, г. Улан-Удэ, ул. Ранжурова, 6 \\ oaelun@mail.ru

\section{(C) Филимонова Екатерина Владимировна} \\ магистрант, \\ Бурятский государственный университет имени Доржи Банзарова \\ Россия, 670000, г. Улан-Удэ, ул. Ранжурова, 6 \\ ekaterinafilimonova72227@gmail.com
}

\begin{abstract}
Аннотация. Рассматривается первый роман И. С. Тургенева «Рудин», в котором представлен герой, сущностно и ментально находящийся между Западом и Россией. Выделено противоречие между умом и сердцем как главное в образе Рудина. Отмечены качества его ума как ведущего способа мышления, самоосмысления и установления контакта с окружающими. Констатируется противопоставление Рудина и Пигасова в аспекте разных истоков их типов ума. Уточняется круг чтения Рудина и восприятие им немецкой литературы. Анализируются сцены признаний в любви и сцена расставания, которые позволяют в герое увидеть особенности его личности.
\end{abstract}

Ключевые слова: роман И. С. Тургенева «Рудин»; драма героя; портрет; тип ума.

\section{Для цитирования}

Башкеева В. В., Филимонова Е. В. Драма героя романа И. С. Тургенева «Рудин»: между Западом и Россией // Вестник Бурятского государственного университета. Филология. 2021. Вып. 1. С. 41-48.

В своем первом романе «Рудин» (1855) Тургенев стремился запечатлеть героя, который не может найти самого себя, не может самоосуществиться. Глубинное противоречие, присущее герою, но так и не осознанное им до конца, составляет драматизм его жизни. Уже портрет Рудина в момент его появления позволяет понять это: «Вошел человек лет тридцати пяти, высокого роста, несколько сутуловатый, курчавый, смуглый, с лицом неправильным, но выразительным и умным, с жидким блеском в быстрых темно-синих глазах, с прямым широким носом и красиво очерченными губами. Платье на нем было не ново и узко, словно он из него вырос» [7, с. 33-34]. Отчетливо выступает в портрете не простой контраст, но антагонизм: высокого роста и сутуловатости, умного лица и жидкого блеска в глазах, узкое платье, из которого он как бы вырос, широкая грудь и тон- 
кий звук голоса, и этот антагонизм сразу подчеркивает непростую природу данного персонажа. Дальнейшее повествование будет только усиливать контраст между умом и поведенческими странностями, переходящими в своеобразное безрассудство.

В определенном отношении Рудин - продолжение типа Чацкого. Горький выкрик героя Грибоедова «ум с сердцем не в ладу» почти буквально соотносим с пожеланием Рудина в прощальном письме Наталье. Герой Тургенева также выделяет две стороны в человеческой личности - сердце и ум: «Мне недостает, вероятно, того, без чего так же нельзя двигать сердцами людей, как и овладеть женским сердцем; а господство над одними умами и непрочно и бесполезно» [7, c. 100].

Что такое ум Рудина и почему он не связан с сердцем? Ум - основной инструмент познания мира и база взаимодействия Рудина с другими людьми. Именно с помощью ума он производит первое и сильное впечатление на общество. Не случайно Александра Павловна удивляется «необыкновенному уму» Рудина, а впечатленная хозяйка дома назовет его гением. Сила его ума именно в общих рассуждениях, в философическом развертывании идей, в создании «громадных картин», отсюда и соответствующие темы: о «значении просвещения и науки, об университетах и жизни университетской вообще», о «вечном значении временной жизни человека», о «достоинстве человека», о «трагическом в жизни и в искусстве» и другие. Овладел Рудин и методом диалектики, судя по всему, гегелевской, ведь именно о понимании истины Гегелем спрашивает он Пигасова. «Стремительная и страстная диалектика» отмечает его речь во время спора.

Уже годы московского студенчества и общения в кружке Покорского показали вовлеченность русских студентов в европейскую философскую проблематику, пестование ума Рудина по образцам, пришедшим из Европы. Уже тогда сам тип ума Рудина вполне соответствовал книжному, генерализующему типу ума: «...тотчас же из прочитанного извлекал все общее, хватался за самый корень дела» [7, с. 67]. Сам этот юный восторг, который описал Лежнев, вспоминая молодость, весьма близок как гегелевским поискам «разумной необходимости и красоты», так и романтическим исканиям идеала. Еще до Германии стремление познать всю полноту истины, в ее очевидных и неочевидных формах, завораживает Рудина и его товарищей: «...все получало значение ясное и в то же время таинственное, каждое отдельное явление жизни звучало аккордом, и мы сами... чувствовали себя как бы живыми сосудами вечной истины» [7, с. 67].

Особенностью умного человека этого времени становится признание значимости науки. Разумеется, Рудин как бывший студент, по сути и оставшийся в душе вечным студентом, высоко ценит науку и выделяет ее как важнейшую часть бытия в диалоге с Натальей: «Вся цель науки - дойти сознательно до того, что молодости дается даром» [7, с. 53]. Для него наука, ученость становятся критерием оценки человека, не случайно он невысоко оценивает своего знакомца барона, которого не без превосходства объявляет «полуученым, полусветским человеком, то есть дилетантом, то есть, говоря без обиняков, - ничем» [7, с. 46]. Сам же Рудин трансформировал науку в своей жизни в коллекционирование, систематизацию и объяснение жизненных явлений, в частности применил почти энтомологический подход к юношеским отношениям Лежнева, когда каждое 
B. В. Башкеева, Е. В. Филимонова. Драма героя романа И. С. Тургенева «Рудин»: между Западом и Россией

чувство, мысль, действие, «каждое движение жизни» стремился «пришпиливать словом, как бабочку булавкой».

Герой высоко оценивает свой ум, гордится им. Характерен образ яблони, на которую он, ссылающийся на отсутствие денег для поездки в Петербург как город трудов и поприща, указывает Наталье. Яблоня сломалась, не выдержав тяжести многочисленных своих плодов, - «верная эмблема гения». И надо понимать, что гением оказывается сам Рудин, в чем обнаруживается нетипичная для русского человека горделивость.

Именно ум позволяет ему овладевать вниманием общества, быть красноречивым, не как «опытный говорун», но как увлеченный идеей энтузиаст. Вот этот ораторский дар, умение покорять другие умы намекают, что его ум особого свойства, ум трибуна, просветителя. И благодарные ученики, в лице Натали, студента Басистова, всегда найдутся.

У Рудина есть двойник - умник Пигасов, который так же, как его визави, способен к высказыванию интересных идей, к удержанию внимания общества на себе. Афористичный тип мышления, характерный для Пигасова с его остроумными классификациями, неожиданными поворотами мысли, оригинальными идеями, соотносится с определенной европейской традицией - традицией французского Просвещения ${ }^{1}$. Остроумие его, правда, оборачивается желчностью, Пигасов становится старым брюзгой. Данный персонаж может рассматриваться как старший собрат Рудина и в целом указывать на то, что апология ума далеко не в 40-е гг. XIX в. стала модной в дворянских салонах и усадьбах. Рудин же как мыслящий человек сформировался - вне зависимости от места формирования - в фарватере европейского Просвещения, одной из ветвей которого стали более всего ценимые им немецкая романтическая философия и литература XVIII-XIX вв.

Новый тип ума - ум Рудина, диалектически рассуждающего о самых разных общих вопросах, - напрямую связан с германской культурой: «Рудин был весь погружен в германскую поэзию, в германский романтический и философский мир» [7, с. 60]. Не случайно он просвещает Наталью именно в этом направлении: читает ей Гете, Гофмана, письма Беттины фон Арним, Новалиса. Интересно, что подбор имен достаточно широкий, в нем суммарно представлена вся значимая немецкая доромантическая и романтическая культура. Это и «веймарский классицизм», и школа иенских романтиков, и гейдельбергцы, и Гофман, в целом стоящий особняком, серьезно повлиявший на русскую романтическую повесть 30-х гг. XIX в. [7, с. 60].

Особо в этом списке выделены письма Беттины фон Арним, скорее всего это «Переписка Гете с ребенком» (1835), шокировавшая в свое время немецкую чи-

\footnotetext{
${ }^{1}$ Теснейшая связь русской культуры с европейской очевидна и по другим персонажам. Дарья Михайловна Ласунская воплощает те поколения русской дворянской элиты, которые глубочайшим образом были связаны с французской культурой, но уже стремились отдать дань новым модным веяниям - русским. Смешение галлицизмов с русским просторечием создавало «странную пестроту» ее речи. Лежнев же в молодости был увлечен английским романтизмом, даже «целую драму» сочинил, в которой подражал «Манфреду» Байрона. «В числе действующих лиц был призрак с кровью на груди, и не со своей кровью, заметьте, а с кровью человечества вообще...» [7, с. 69].
} 
тающую публику. Поражала сама ситуация, когда проявлялись игра взрослого человека в роли ребенка, обращение к годящемуся ей в отцы Гете на «ты», весь ее эксцентричный облик и поведение и какая-то настойчивая, назойливая и почти маниакальная презентация любви квазиребенка: «Я не стану уверять тебя в любви; ты видишь ее в каждой моей мысли и в той потребности, которую всегда я ощущаю, раскрывать перед тобой все мое бедное сердце» [1].

Для нас сегодня важно не столько то, кому Рудин это читает и толкует, сколько то, что сам он принял и, скорее всего, признал и европейский феминизм, и разрушение возрастной дистанции, и экзальтацию выставления себя напоказ, и шокирующую женскую исповедальность. Вот часть того европейского ментального поля, которое закрепило дискуссии и бдения московских студентов и почти навсегда отторгло его от русской ментальности.

Воспитание в рамках европейской культуры и своеобразная речевая талантливость Рудина сформировали особый тип личности, который не может приспособиться к русской жизни. В последней четверти XIX в. Н. Н. Страхов так объяснил этот феномен «русских европейцев», перекати-поле русской культуры: «Без сомнения, коренное наше зло состоит в том, что мы не умеем жить своим умом, что вся духовная работа, какая у нас совершается, лишена главного качества: прямой связи с нашей жизнью, с нашими собственными духовными инстинктами. Наша мысль витает в призрачном мире; она не есть настоящая живая мысль, а только подобие мысли. Мы - подражатели, то есть думаем и делаем не то, что нам хочется, а то, что думают и делают другие. Влияние Европы постоянно отрывает нас от нашей почвы... наша злоба и любовь устремлены на призраки; наши жертвы и подвиги совершаются ради мнимых целей» [5, с. 1].

Современный исследователь пишет об этом так: «Он биографически приобщается к европейскому цивилизующему началу - воспитывается, образовывается, просвещается в русле западном, приемлет и приветствует основы европейской культуры. Но в силу своей ментальности остается при этом человеком русским, европейски образованным русским, что немало осложняет его жизнь в России» [4]. О разладе, происходящем «в душевном мире героев Тургенева 18401850-х гг., их подлинной трагедии, которая обрекла их на бессмысленное существование», пишет другой автор [3].

В Рудине нет выдержки и меры, в определенных ситуациях в нем нет деликатности и такта. Невообразимо странным становится его визит к Волынцеву на следующий после объяснения с Натальей день. Визит был абсолютно необязательный, «навязчивый и нескромный», что чувствует Волынцев, а степень откровенности, которую выбирает Рудин, шокирует. Причем «откровенность, полную откровенность» он считает чуть ли не обязанностью, своим долгом. Подобный перекос и непонимание, как вести себя, как раз и показывают, к каким причудливым жизненным формам может привести «смешение французского с нижегородским».

Эта вечная серьезность ума, это создаваемое в течение многих лет реноме умного серьезного человека, рассуждающего о высоких материях, - своего рода ментальная и поведенческая клетка, в которой оказывается заперта живая душа Рудина. Интересна портретная деталь Тургенева, связанная со смехом Рудина, для которого непривычно подобное состояние: он вообще смеялся «очень редко», 
B. В. Башкеева, Е. В. Филимонова. Драма героя романа И. С. Тургенева «Рудин»: между Западом и Россией

и в это время «лицо его принимало странное, почти старческое выражение, глаза ежились, нос морщился...» [7, с. 47]. Как будто инстинктивно герой стремится сохранить ментальный контроль над неподобающим состоянием, в которое не должен впадать серьезный человек.

Ум маскирует у Рудина его слабость - неуверенность в себе. Он не уверен, есть ли у него талант («Я не должен скрывать свой талант, если он у меня есть») [7, с. 54], и, очевидно, это тот талант, какой, по мысли немецких романтиков, является знаком избранности личности. Он не уверен и в том, готов ли к поприщу, к деланию большого дела, сможет ли преодолеть «малодушие и лень». Он понимает и то, что слово его избыточно, критикует свою «пустую, бесполезную болтовню». Позже, в прощальном письме к Наталье, он впадет в крайность абсолютной неопределенности: «Мне недостает... я сам не могу сказать, чего именно недостает мне...» ${ }^{1}[7$, с. 101].

Как мы можем видеть, для русского последователя европейского просвещения не существует целостной концепции личности. Она разъединена на два, во многом антагонистичные, начала. Причем если у Чацкого сердце пылало, а сюжет строится на стремлении узнать загадки любимой, и такой антагонизм не исключает дуализма, невозможности двум началам существовать друг без друга, то Рудин холоден, сердце его молчит. По словам Лежнева, лучше всех знающего его, он «холоден, как лед, и знает это и прикидывается пламенным» [7, с. 63], «в душе был холоден и чуть ли не робок, пока не задевалось его самолюбие»² [7, с. 66].

Эта холодность Рудина даст о себе знать как о человеческой мужской несостоятельности и в сцене признания в любви, и в сцене решающего объяснения с Натальей у Авдюхина пруда. В первой сцене герой встает на котурны, играет роль страстного, внезапно прозревшего, влюбленного человека. Показательны при этом начальная и финальная портретные детали. Наталью он ждет, «скрестив руки на груди». Эта поза и этот жест привычны для изображения Лермонтовым Наполеона - «и две руки, сложенные крестом». В присвоении такого движения видится ощущение своей значительности и даже величия. Но в конце, после ухода Натальи, он засомневался в том, счастлив ли он обоюдным признанием, и после этого «пошел проворно в сад, весело размахивая руками» [7, с. 79]. В такой проворности и веселости ощутимы отнюдь не лирические эмоции, а деловая энергия и довольство собой.

В свидании у Авдюхина пруда он также, с «сосредоточенной решимостью», «скрещивал руки на груди», при этом картинно стоял прямо на плотине. Служанка Маша сразу отметила его невписанность в ситуацию: стоит на самом виду - «на яру», а надо бы спуститься в лощину. Житейский смысл и умение подумать о других не характерны для героя. В каком-то смысле он непутевый человек, все не может найти свой путь, может быть, потому, что пути у него нет.

\footnotetext{
${ }^{1}$ Небезынтересно, что Волынцев, соперник Рудина в отношениях с Натальей, также не вполне уверен в себе. Расстроенный интересом Натальи к Рудину, он глядел «грустным зайцем», но никак не борющимся за свое счастье человеком.

${ }^{2}$ Внутренняя холодность Рудина как бы передалась Наталье в момент ее страдания: «Есть слезы холодные, скупо льющиеся слезы»; «...посмотрела с холодной улыбкой на себя в зеркало» [7, с. 102].
} 
Завершение фрагмента показывает другого, почти обновленного Рудина. Расставаясь с Натальей, он терял не только возможность общения с молодой, интересной для него девушкой, но и получал отставку от дома, а для него при бедности и бесприютности это был крайне неприятный удар. И поэтому герой уже не играет роль, поскольку, потрясенный, «он долго еще стоял на плотине. Наконец он встрепенулся, медленными шагами добрался до дорожки и тихо пошел по ней» [7, с. 91].

В финале опубликованного Тургеневым в 1856 г. первого варианта романа Лежнев, полемизируя с Пигасовым, начнет защищать приятеля юности и отделит жар мысли, «голову» Рудина от его натуры, природы: «Холодность эта у него в крови - это не его вина, - а не в голове» [7, с. 110]. Позднее, в добавленном эпилоге, в диалоге с постаревшим, потерявшим надежду Рудиным Лежнев самого себя назовет «холодной кровью». Холодность в крови - это отсутствие у Рудина натуры, то есть характера, природы, какой-то органической силы. Это не темперамент, но нечто, существующее за пределами ума. По сути, теперь речь идет о характере героя, о восприятии русского человека как медлительного, неповоротливого, неподвластного чувствам, байбака, что и должно было извинить и оправдать Рудина.

Лежнев станет идеологом русскости. Европеец у него связан с «философическими хитросплетениями и бреднями» - тенденциями явно неположительными, а русский человек силен «здравым смыслом». Русскому нельзя становиться космополитом: «космополит - нуль, хуже нуля»; народность же как обозначение русского национального начала для Лежнева - исток художества, истины, жизни. Именно народность, то есть национальность, дает человеку «физиономию», основу своеобразия личности.

Наконец Лежнев констатирует основу несчастий Рудина: «России не знает». И чеканно формулирует удивительную для Тургенева максиму: «Россия без каждого из нас обойтись может, но никто из нас без нее не может обойтись» [7, с. 111]. Не может, кстати, и Рудин. При этом он не может в России не только жить, не может даже и умереть. Для этого ему приходится вернуться в Европу.

Дописанный через четыре года эпилог вносит новые ноты в созданный писателем образ. Суть эпилога - в реабилитации Рудина. Наконец он является в попытках дела, а не только в ярком монологе, или, по словам самого Рудина, во фразе. Все три дела, о которых он поведал Лежневу, были предприняты с желанием добра, но ни одно из них не имело под собой серьезных оснований. Не было понимания агрономического дела для внедрения усовершенствований в имении некоего богача, не было денег для проекта судоходной реки, не было понимания педагогического дела и методики на службе преподавателя русской словесности. Иначе говоря, не было самого главного. Причем сам Рудин почти понимает, что он пускает «мыльные пузыри», но остановиться и не делать этого не может. Действие состоялось, но оказалось пустым. При этом ни его автоинтерпретация (судьба «сопрет меня» с известной точки) или констатация отсутствия дел, ни восприятие Лежневым слова как дела не могут быть окончательными.

Исследователи, изучающие влияние Германии, немецкой философии, литературы, музыки на Тургенева, склонны расценивать его героев как тех, кто испы- 
B. В. Башкеева, Е. В. Филимонова. Драма героя романа И. С. Тургенева «Рудин»: между Западом и Россией

тывает русскую жизнь, или русскую провинцию. Применительно к повести «Гамлет Щигровского уезда» подобную позицию занимает В. Кантор: «Дело здесь не просто в русской провинции..., а в точечных вкраплениях людей высокой культуры в эту провинцию, в столкновении людей, воспитанных на Гегеле и Шеллинге, привыкших к рефлексии и философствованию, с обывателями, живущими только бытом, причем бытом нецивилизованным...» [2, с. 133]. С этим мнением трудно согласиться, при всей увлеченности Тургенева немецкой культурой.

Применительно к Рудину, если бы он продемонстрировал непротиворечивость характера, внутреннюю уверенность в себе, успешность прохождения жизненного пути, тогда бы имело смысл говорить об испытании русского быта европейским образом мысли и европейским этикетом. Рудин же сам признает свое фиаско. Более верной представляется традиционная интерпретация - испытание героя русской жизнью.

Интерпретация эта видна в сравнении романа с повестью «Гамлет Щигровского уезда» (1848), герой которой признается: «Я бы и рад был брать у ней уроки, у русской жизни-то, - да молчит она, моя голубушка» [6, с. 235]. В ранней повести Тургенева рефлексия была выведена в текст, а акцент сделан на очевидных недостатках героя, попытавшегося вписать себя в русскую жизнь, но вынужденного отодвинуться на ее обочину. В романе «Рудин» преобразование героя произошло таким образом, что его сильные качества, напротив, выдвинулись, а рефлексия, психологическая или идеологическая, оказалась затемнена, что и привело к сложности интерпретации образа, увы, не как «русского европейца», а скорее «нерусского западника».

\section{Лumepamypa}

1. Гете И. В. Избранная переписка с Беттиной Брентано и И.-Г. Мерком. URL: http://www.librapress.ru/2018/09/gyote-izbrannaya-perepiska-s-bettinoj-brentano-i-i-gmerkom.html (дата обращения: 20.03.2021). Текст: электронный.

2. Кантор В. К. Иван Тургенев: Россия сквозь «магический кристалл» Германии // Вопросы литературы. 1996. № 1. С. 121-158. Текст: непосредственный.

3. Малышева Л. Г. Германия в творчестве И. С. Тургенева 1840-50-х годов (к вопросу о «лишних людях») // Вестник ТГПУ. 2010. Вып. 8 (98). URL: https:/cyberleninka.ru/ article/n/germaniya-v-tvorchestve-i-s-turgeneva-1840-50-h-godov-k-voprosu-o-lishnih-lyudyah (дата обращения: 19.03.2021). Текст: электронный.

4. Постникова Н. Н. Тема Германии в романах И. С. Тургенева: автореферат диссертации на соискание ученой степени кандидата филологических наук. Вологда, 2007. URL: https:/www.dissercat.com/content/tema-germanii-v-romanakh-turgeneva (дата обращения: 21.03.2021). Текст: электронный.

5. Страхов Н. Н. Борьба с Западом в нашей литературе. Кн. 1. 2-е изд. СанктПетербург, 1887.

6. Тургенев И. С. Гамлет Щигровского уезда // И. С. Тургенев. Собрание сочинений: в 5 т. М.: Русская книга, 1994. Т. 1. 544 с. Текст: непосредственный.

7. Тургенев И. С. Рудин // Тургенев И. С. Собрание сочинений: в 5 т. Москва: Русская книга, 1994. Т. 4. 416 с. Текст: непосредственный.

Статья поступила в редакцию 24.11.2020; одобрена после рецензирования 28.01.2021; принята к публикации 25.03.2021. 


\section{DRAMA OF HERO IN «RUDIN» BY IVAN TURGENEV: BETWEEN WEST AND RUSSIA}

Vera V. Bashkeeva

Dr. Sci. (Phil.), Prof.,

Dorzhi Banzarov Buryat State University

6 Ranzhurova St., Ulan-Ude 670000, Russia

oaelun@mail.ru

Ekaterina V. Filimonova

Research Assistant,

Dorzhi Banzarov Buryat State University

6 Ranzhurova St., Ulan-Ude 670000, Russia

ekaterinafilimonova72227@gmail.com

Abstract. The article reviews the first novel by Ivan Turgenev «Rudin», where the hero is mentally and essentially placed between the West and Russia. The contradiction between the mind and the heart is highlighted as the main feature in the image of Rudin. The qualities of his mind are the main mode of his thinking, reflecting and establishing contact with people around. The contrast between Rudin and Pigasov is shown in the aspect of different origins of their minds. The article demonstrates Rudin's interest in reading and German philosophy, and analyzes the scenes of declaration of love and breaking up which allow to understand the features of his personality.

Keywords: novel «Rudin» by Ivan Turgenev; drama of hero; portrait; type of mind.

For citation

Bashkeeva V. V., Filimonova E. V. Drama of Hero in «Rudin» by Ivan Turgenev: Between West and Russia. Bulletin of Buryat State University. Philology. 2021; 1: 41-48 (In Russ.).

The article was submitted 24.11.2020; approved after reviewing 28.01.2021; accepted for publication 25.03.2021. 